\title{
CLINICOPATHOLOGICAL ANALYSIS OF OVARIAN TUMOURS IN A TERTIARY CARE INSTITUTE AND THE ROLE OF ER, PR AND HER-2/neu IN SURFACE EPITHELIAL TUMOURS OF OVARY
}

\author{
Thangaraj Priya ${ }^{1}$, Alagappan Santhi ${ }^{2}$
}

${ }^{1}$ Assistant Professor, Department of Pathology, Thanjavur Medical College, Thanjavur, Tamilnadu, South India. 2 Professor and HOD, Department of Pathology, Thanjavur Medical College, Thanjavur, Tamilnadu, South India.

\section{ABSTRACT}

\section{BACKGROUND}

Ovarian tumours account for $6 \%$ of all cancers in women and is the 5th leading cause of death in women in India. Ovarian neoplasms are increasingly important not only because of the diverse entities, but more so because they have gradually increased the mortality due to female genital cancers.

\section{OBJECTIVES}

1. To evaluate the incidence of ovarian tumours in our institution.

2. To evaluate ER, PR and Her-2/neu expression in primary surface epithelial tumours.

3. To evaluate Her-2/neu amplification in distinguishing borderline and malignant surface epithelial tumours.

\section{MATERIALS AND METHODS}

A total of 2755 gynaecological cases were received at Department of Pathology, Thanjavur Medical College, Thanjavur, during the period of January 2013 to May 2015. Of this 132 ovarian neoplasms received were studied to find out the different histological patterns at our tertiary care institute. Sections of $4 \mu$ thickness were taken from paraffin embedded tissue blocks for H\&E and IHC Out of 26 malignant surface epithelial tumours reported ER, PR, Her-2/neu expression was studied in 11 cases, also expression of HER 2/neu in 5 borderline cases were studied.

\section{RESULTS}

Among the 132 ovarian tumours, majority 97 (73.4\%) were benign, 26 (19.6\%) were malignant and remaining 9 cases were borderline. The commonest histological pattern observed in the study was surface epithelial tumours (68.9\%) followed by germ cell tumours (24.2\%). Positive expression of steroid receptors (ER, PR) in malignant surface epithelial tumours proves their mitogenic role. Her-2/neu was expressed only in malignant tumours and not in borderline tumours. The above fact helps in distinguishing borderline and malignant tumours.

\section{KEYWORDS}

Epithelial Ovarian Tumours, Her-2/neu, Steroid Receptors.

HOW TO CITE THIS ARTICLE: Priya T, Santhi A. Clinicopathological analysis of ovarian tumours in a tertiary care institute and the role of ER, PR and HER-2/neu in surface epithelial tumours of ovary. J. Evolution Med. Dent. Sci. 2016;5(55):3774-3779, DOI: $10.14260 /$ jemds/2016/865

\section{INTRODUCTION}

Ovarian cancer is the $6^{\text {th }}$ most common cancer in women worldwide. It is the $5^{\text {th }}$ leading cause of death among women in the developed countries.[1,2] The incidence rate is higher in white women followed by Hispanic, Asians, Black and American Indian women. ${ }^{[3]}$

In India, the Age Standardized incidence Rate (ASR) for ovarian Carcinoma varied from 0.9 to 8.4 per $1,00,000$ person/year. Studies revealed that the peak incidence is in between the age of 55-64 years. The mean annual percentage increase in ASR ranges from 0.7 to $2.4 \% .^{[3]}$

\section{The Risk Factors Associated with Ovarian Tumours are}

1. Age

2. Positive family history

3. Genetic factors

4. Hormonal influences

5. Reproductive factors. ${ }^{[4]}$

Financial or Other, Competing Interest: None.

Submission 30-05-2016, Peer Review 27-06-2016,

Acceptance 04-07-2016, Published 11-07-2016.

Corresponding Author:

Dr. Thangaraj Priya,

F-16, Royal Denizen,

Pattabiraman Street,

Thennur, Trichy-620017.

E-mail:drpriyajai@gmail.com

DOI: $10.14260 /$ jemds/2016/865
It has been suggested that incessant ovulation and gonadotropin stimulation may play a role in development of ovarian cancer.[5] Predominantly, ovarian neoplasms are sporadic in nature. About $5-10 \%$ of ovarian cancers are hereditary. These women have inherited mutations in BRCA1 and BRCA-2, tumour suppressor genes.[4,6]

For diagnosis of early ovarian cancer, abdominal USG and serum CA-125 were used as screening methods. FNAC can be used to differentiate benign from malignant ovarian tumour with an accuracy of 90-95\%.[7] Despite these screening methods, ovarian neoplasm carries the highest mortality among all the gynaecological cancers. This is due to the fact that the early stages are asymptomatic. The tumour is diagnosed only in late stages (Stage III and IV). No effective screening methods are available as in cervical cancer.

A 5 -year survival rate is around $40 \%$. In late stages, it is only $10-20 \%$. The above scenario is due to paucity of knowledge about exact aetiological factors.[8] Histological grading is an important prognostic factor in the surface epithelial stromal tumours. Also sub-typing of surface epithelial stromal tumours into Benign, Borderline and Malignant has important influence on therapeutic and prognostic point of view.

Following introduction of CA-125 in 1981 as biomarker for epithelial ovarian carcinoma, numerous biomarkers have been emerging substantially.[9] Epidemiological evidence 
suggests that steroid hormones (Oestrogen and progesterone) and amplification of human epidermal growth factor-2 (Her-2/neu) gene are implicated in ovarian carcinogenesis.[1,2] Limited number of clinical trials have demonstrated efficacies of anti-oestrogen and progesterone alone or in combination with chemotherapeutic drugs in the treatment course.[1]

Thus the steroid hormone receptor positivity on the ovarian surface epithelium and ovarian carcinoma is of paramount significance for hormonal therapy. The above strategy paves way for novel therapies in the prevention and treatment of ovarian carcinoma.[10]

This study is undertaken to review the incidence of ovarian neoplasms in our institution. This study is done with reference to age, histopathological, clinicopathological, immune-histochemical features in concordance with review of journals and various research publications.

\section{MATERIALS AND METHODS}

This study is a retrospective study carried out in Department of Pathology, Thanjavur Medical College from January 2013 to May 2015. A total of 132 cases of ovarian neoplasms referred from Raja Mirasudhar Government Hospital (RMH) were included in this study.

The gross specimens were fixed in 10\% neutral buffered formalin and processed routinely. Clinical history of the patient including the age, examination findings, radiological investigation, USG, CT and FNAC reports were evaluated in detail.

4 to 5 bits including the wall with papillary excrescences were taken for cystic ovarian neoplasms; 3 to 4 bits were taken in solid tumours of size less than $5 \mathrm{cms}$. In variegated tumours more than $5 \mathrm{cms}$, one block per $1 \mathrm{~cm}$ of the tumour was taken in its greatest dimension. Section of 3 to $4 \mu \mathrm{m}$ were cut and stained with haematoxylin and Eosin.

The H\&E stained slides were reviewed. Parameters consisting of age, tumour size, stage of the disease (FIGO Staging) and histological typing were done according to WHO classification criteria. Serous carcinoma were graded according to recent two-tier grading system.

The immune-histochemical detection of steroid hormonal status (ER, PR) in surface epithelial stromal tumour were conducted. Also the status of Her-2/neu amplification in borderline and malignant tumours were studied.

\section{ER, PR, HER-2/NEU STAINING}

Representative $4 \mu \mathrm{m}$ sections were taken from paraffin embedded blocks for Immuno-histochemistry (IHC). The procedure was performed according to heat-induced epitope retrieval method with specific antibodies against ER, PR and Her-2/neu.

Scoring for ER and PR expression was based on the following criteria. Proportion of cells exhibiting distinct nuclear immune-staining and intensity of staining was taken into consideration.

The results were given as Negative $(<10 \%)$ and Positive $(\geq 10 \%)$. $[11]$

Her-2/neu positivity was assessed using Ellis and Wolf recommendations.[12]
Score
$1+$
$2+$
$3+$

\section{Staining Pattern}
(1)
Barley perceptible membrane staining in $>10 \%$ of cells.
Weak-to-moderate complete membrane, staining present in $>10 \%$ of tumour cells. Strong, complete membrane staining in $>10 \%$ tumour cells.

\section{RESULTS}

$\begin{array}{lll}2+ & \text { Equivocal } & \\ 3+ & \begin{array}{l}\text { Positive, cytoplasmic staining was } \\ \text { considered non-specific. }\end{array} & \end{array}$

A total of 132 cases were evaluated in concordance with clinical history, histopathological and immunehistochemistry.

Ovarian malignancy $(4.1 \%)$ is the second most common malignancy in female genital tract next to cervical malignancy. In age groups, ovarian neoplasms are commoner in $2^{\text {nd }}$ decade and in $4^{\text {th }}$ decade.

The ratio of benign and malignant ovarian neoplasm is 3:1. Predominantly, they presented as unilateral tumours (90\%) than bilateral (10\%). Grossly, benign tumours presented as cystic neoplasms and the malignant tumours presented as solid and cystic or purely solid. Regarding histological type, surface epithelial tumours (68.9\%) are the most common neoplasm among which mucinous cystadenoma is the commonest (Table 1). Positive expression of ER, PR (Steroid receptors) in surface epithelial malignancies proves the mitogenic role of oestrogen in ovarian tumours. PR expression may be related to oestrogenic regulation. The expression of steroid receptors paves way for antihormonal therapy. Her-2 neu was expressed only in malignant tumours. This suggests their carcinogenic role. This also helps in differentiating borderline and malignant tumours.

\begin{tabular}{|c|c|c|c|c|}
\hline $\begin{array}{l}\text { Sl. } \\
\text { No. }\end{array}$ & Classification & $\begin{array}{l}\text { No. of } \\
\text { Cases }\end{array}$ & $\begin{array}{l}\text { Total } \\
\text { Cases }\end{array}$ & $\%$ \\
\hline 1. & $\begin{array}{c}\text { Surface } \\
\text { Epithelial Tumour } \\
\\
\text { Benign } \\
\text { Borderline } \\
\text { Malignant } \\
\end{array}$ & $\begin{array}{c}64 \\
9 \\
18 \\
\end{array}$ & 91 & $68.9 \%$ \\
\hline 2. & $\begin{array}{c}\text { Germ Cell Tumour } \\
\text { Benign } \\
\text { Malignant } \\
\end{array}$ & $\begin{array}{c}29 \\
3 \\
\end{array}$ & 32 & $24.2 \%$ \\
\hline 3. & $\begin{array}{c}\text { Mixed Germ Cell } \\
\text { Tumour }\end{array}$ & 1 & 1 & $0.75 \%$ \\
\hline 4. & $\begin{array}{c}\text { Sex Cord Stromal } \\
\text { Tumour } \\
\\
\text { Benign } \\
\text { Malignant }\end{array}$ & $\begin{array}{l}4 \\
2\end{array}$ & 6 & $4.5 \%$ \\
\hline 5. & Metastatic & 2 & 2 & $1.5 \%$ \\
\hline & Total & 132 & 132 & \\
\hline \multicolumn{5}{|c|}{ Table 1} \\
\hline
\end{tabular}

Sub-Classification of Surface Epithelial Tumours 
The surface epithelial tumours are classified according to WHO HISTOLOGICAL CLASSIFICATIONS and is as follows in Table 2.

\begin{tabular}{|c|c|c|c|c|}
\hline $\begin{array}{l}\text { Sl. } \\
\text { No. }\end{array}$ & Classification & $\begin{array}{l}\text { No. of } \\
\text { Cases }\end{array}$ & $\%$ & Average \\
\hline \multirow[t]{2}{*}{1.} & $\begin{array}{c}\text { Serous Tumours } \\
\text { Benign } \\
\text { Borderline } \\
\text { Malignant }\end{array}$ & $\begin{array}{c}28 \\
3 \\
9\end{array}$ & $\begin{array}{c}21.2 \% \\
2.2 \% \\
6.8 \%\end{array}$ & $43.9 \%$ \\
\hline & Total & 40 & & \\
\hline \multirow[t]{2}{*}{2.} & $\begin{array}{l}\text { Mucinous } \\
\text { Benign } \\
\text { Borderline } \\
\text { Malignant }\end{array}$ & $\begin{array}{c}36 \\
6 \\
4\end{array}$ & $\begin{array}{c}27.2 \% \\
4.5 \% \\
3 \%\end{array}$ & $50.5 \%$ \\
\hline & Total & 46 & & \\
\hline \multirow[t]{2}{*}{3.} & $\begin{array}{c}\text { Endometrioid } \\
\text { Malignant }\end{array}$ & 5 & $3.7 \%$ & $5.4 \%$ \\
\hline & Grand Total & 91 & & \\
\hline \multicolumn{5}{|c|}{ Table 2} \\
\hline
\end{tabular}

11 cases out of 26 malignant surface epithelial ovarian tumours were selected for immunohistochemistry. ER, PR expression was evaluated in the 11 malignant surface epithelial ovarian cancer. ER, PR expression was higher in serous and endometrioid tumours when compared to other surface epithelial tumours. Her-2/neu expression is higher in malignant tumour when compared to borderline tumours. In histological types, Her-2/neu expression is higher in highgrade serous carcinoma when compared to low-grade tumours, mucinous and endometrioid carcinomas.

5 out of 9 cases of borderline tumours were selected for immune-histochemical analysis. The expression of Her-2/neu in 2 types (Serous, mucinous) of borderline surface epithelial tumour were studied). All the Borderline tumours showed negative expression of Her-2/neu.

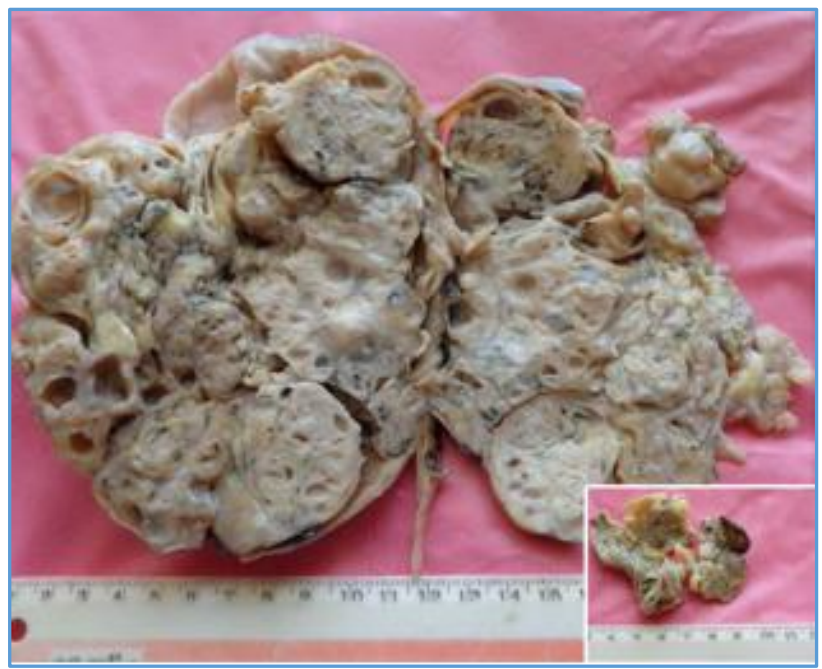

Fig. 1: Immature Teratoma with Gliomatosis Peritonei Cut Surface-Solid and Cystic with Focal Glistening Areas and Implants in Peritoneum

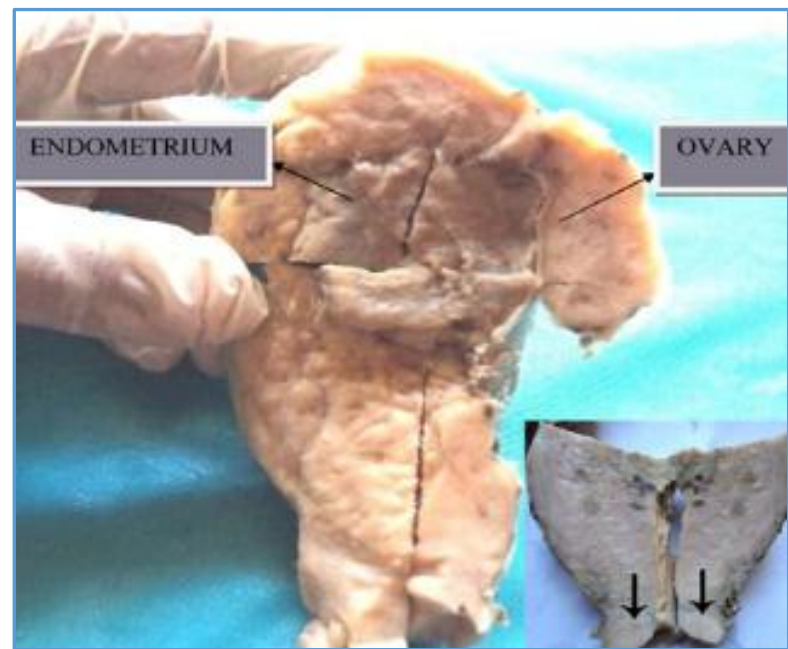

Fig. 2: Bilateral Dysgerminoma with Metastasis in Endometrium and Cervix

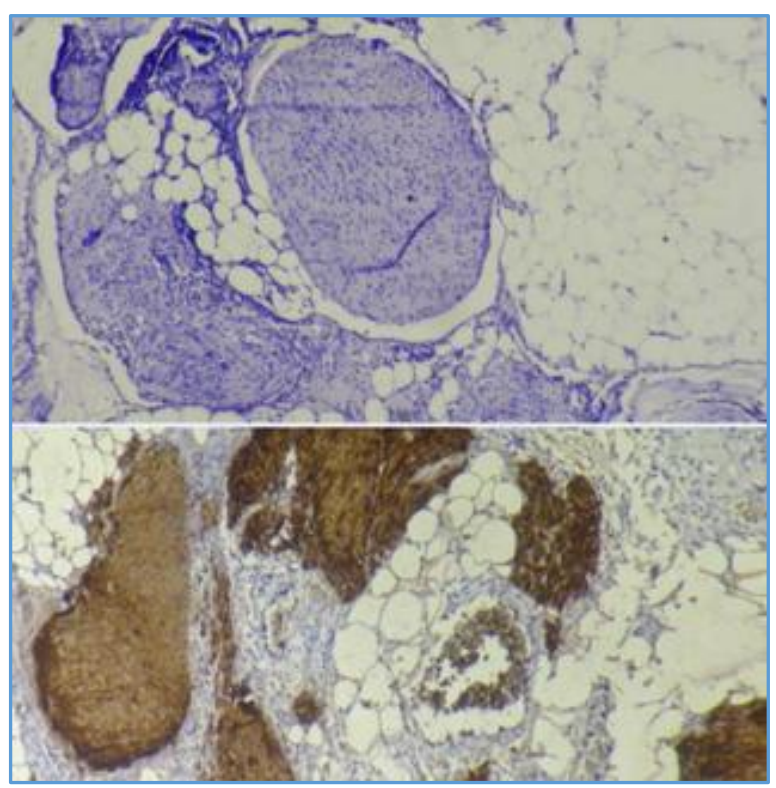

Fig. 3: Gliomatosis Peritonei - Omental Deposits, Positive GFAP Expression

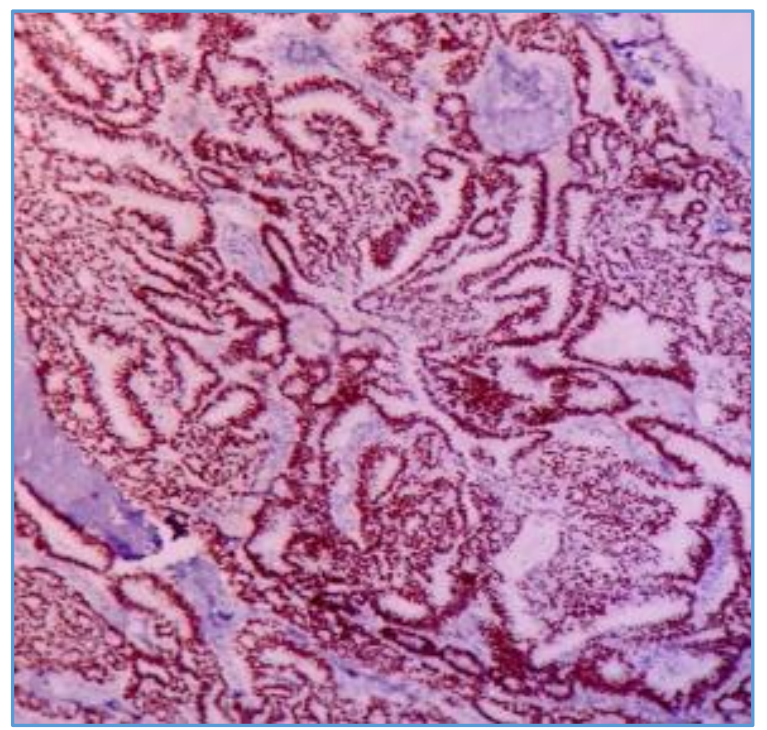

Fig. 4: Endometrioid Carcinoma showing Strong ER Expression, Nuclear Positivity (10x) 


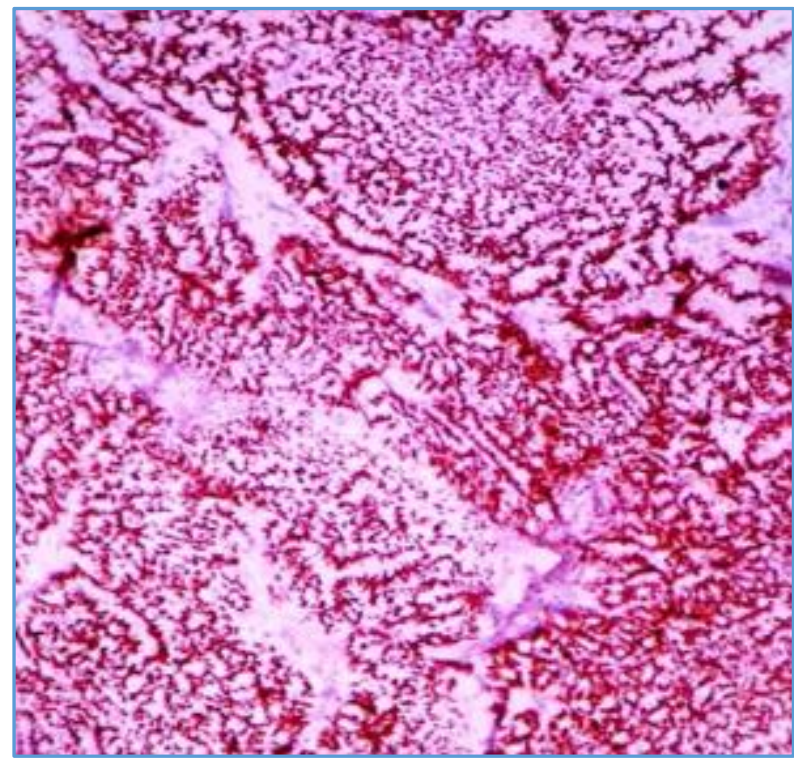

\section{Fig. 5: Endometrioid Carcinoma showing Strong PR Expression, Nuclear Positivity (10x)}

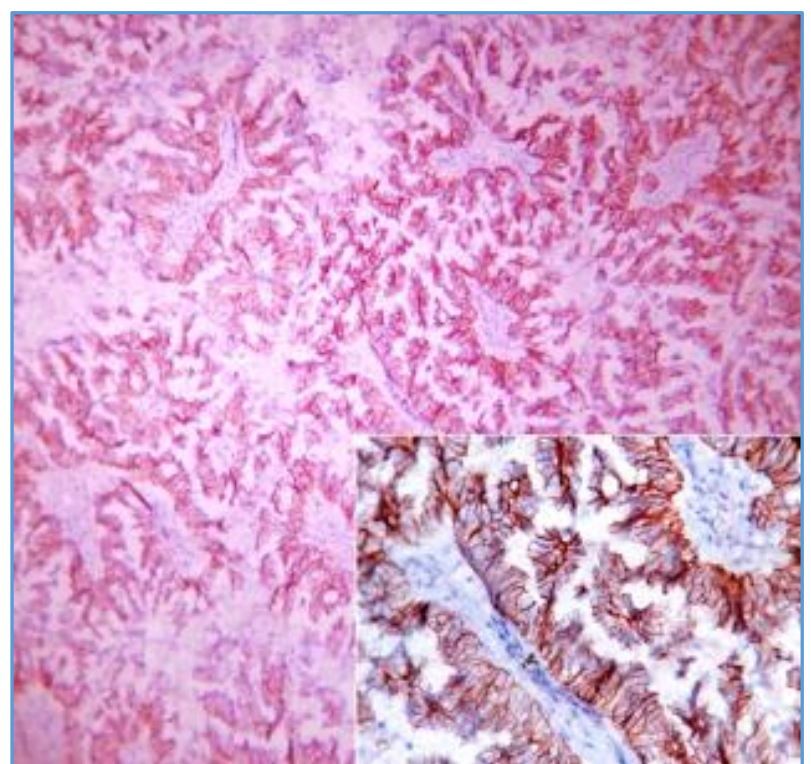

Fig. 6: Her-2/neu Strong 3+ Membranous Positivity in a High-Grade Serous Carcinoma

\section{DISCUSSION}

Ovaries are common sites of non-neoplastic and neoplastic lesions. The constant cyclical changes from puberty to menopause give rise to different cell types, each of which results in varieties of tumours.[13]

The diverse histopathologies in ovarian tumours reflects the different cell origins.[14] Recent Surveillance, Epidemiology and End Result (SEER) calculations of lifetime risk for ovarian carcinoma are that 1 in 55 women will develop ovarian cancer over their lifetime. As the symptoms are vague and manifests over time, ovarian cancers are difficult to detect until they are in advanced stage.[15]

Identification of various histological patterns of ovarian tumours is important in diagnosis, prognosis and treatment of ovarian cancers. Immunohistochemistry is now emerging as an important tool in diagnosis of ovarian tumours. ${ }^{[9]}$ It has been shown that oestrogen and progesterone receptor level depends on histological grade, stage and variables among the tumours of same grade.[16] Her-2/neu is amplified and overexpressed in 25 to $30 \%$ of human ovarian cancers. It is associated with progression of invasive cancer, poor prognosis and resistance to chemotherapy.[17]

In this study, about 14,093 surgical specimens were received over a period of $2 \frac{1}{2}$ years. Of the 631 gynaecological tumours, 132 ovarian neoplasms were reported. This accounts for about $20.9 \%$ of all gynaecological tumours reported in this study. The incidence rate is highest (15.8\%) in developed countries. In India, the incidence rate is highest in Eastern India (9.5\%) and least is Dindigul Ambilikai Cancer registry (3.3\%). This study is undertaken in a semiurban area with an incidence rate of $2.1 \%$. This is midway between a rural and urban area.

Total number of malignancies reported during the study period is 1089. The total ovarian malignancies reported during the study period is 26 . Of this the most common ovarian malignant tumour was papillary serous cystadenocarcinoma. The above equates to $34.6 \%(9 / 26)$ followed by endometrioid carcinoma accounting for $19.2 \%$ (5/26). The least common type is mixed germ cell tumour and immature teratoma. The above data coincides with Samina et al[18] in which surface epithelial tumour constituted $68.5 \%$ and germ cell tumour (23\%). According to Jefferey et al[19], serous borderline tumours presented as commonest type among the borderline tumours. In contrast, our study depicts a higher incidence of mucinous borderline tumours (66.6\%) when compared to serous borderline tumours (33.3\%).

In our study, all the serous borderline tumours were unilateral and none had positive peritoneal implants.

According to Anais Malpica et al[20], ovarian serous tumours are divided into low-grade and high-grade according to recent two of their grading system. The above phenomena is based primarily on nuclear atypia and the secondary feature, mitotic rate.

According to Jefferey SD et al[19], surface epithelial carcinomas are divided into Type I and II based on different pathways of tumourigenesis. According to Robert J. Kurman the low-grade neoplasm arise through stepwise process from borderline endometrioid, malignant Brenner, clear cell carcinomas.[20] Type II tumours arising de novo are aggressive neoplasms. Type II tumours present at advanced stages. These include high-grade serous, malignant mixed Mullerian tumour, undifferentiated carcinoma. In our study, mucinous tumour is the most common surface epithelial tumour of which $78.2 \%$ were benign, $13 \%$ were borderline and $8.6 \%$ were malignant. This is in contrast to the studies of Koonings et al[21], Hiremath et al[15], Misra et al[22] which stated that serous tumours constituted the commonest type of surface epithelial tumours.

According to Jaime et al[23], endometriosis is associated with high incidence of endometrioid, clear cell carcinomas, mucinous and serous carcinoma. In contrast, in our study none of endometrioid carcinoma (5/132) cases were associated with endometriosis.

In our study, 33 cases of germ cell tumours were reported. This constitute about $24.2 \%$ of all ovarian neoplasms. In germ cell tumours mature cystic teratoma is the commonest group, constitutes $90.9 \%$ followed by dysgerminoma $6 \%$ and mixed germ cell tumour $3 \%$. This is in 
concordance with studies of Kwok et al.[24] According to the above author, malignancy in germ cell tumours is associated with post-menopausal age group. This is in contrast to our study, where one case which was reported as immature teratoma was reported in younger age group.

According to P. Singh et al[25], the commonest tumour associated with pregnancy is dermoid cyst. In our study, 2 cases were reported which were associated with pregnancy. One was associated with dermoid cyst, the other case was reported in association with mucinous cyst adenoma. One case of mixed germ cell Tumour was reported. This tumour was a combination of Dysgerminoma and Embryonal carcinoma.

In our study, a total of 6 cases of sex cord stromal tumours were reported. This accounts for about $4.5 \%$ of all ovarian tumours. Granulosa cell tumour, fibroma, fibrothecoma had the same incidence of $33.3 \%$. The above data had no coincidence with any of the studies.

According to Lawrence et al[17], 95\% of granulosa cell tumours are unilateral. All the $2 / 6$ cases in our study were unilateral and none were associated with endometrial hyperplasia.

According to Masakimandai et al[26], 5-10\% of neoplasm arise from metastases. Ovarian metastases have some common features. Some of them are bilaterality, surface involvement, extensive extra-ovarian spread, desmoplastic reaction, vascular invasion and unusual clinical history.[26] In our study, one case of Krukenberg's and one case of metastatic adenocarcinomatous deposit was reported. Both were unilateral in presentation. The Krukenberg's tumour was characterised by the presence of mucin filled, signet ring tumour cells within cellular stroma.

In our study, ER expression is positive in $4 / 11$ cases (36.3\%) cases, PR expression is positive in 5/11 (45.4\%), which coincides with study of Sylvia et al[27] ER, PR has strong expression in endometrioid $(2 / 3,66.6 \%)$ and high-grade serous tumours $(3 / 5$ cases, $80 \%)$ which is similar to findings of Agarwal et al[28] Damia et al.[29] This is in contrast to Buchynska et al[30], who stated that ER expression is lower in high-grade tumour. The above features suggest possible mitogenic role of ER in ovarian tumours and high PR positivity in conjunction with ER expression is indicative of oestrogen regulated disease. Her-2/neu expression is negative in borderline tumours and shows positivity in highgrade malignant tumours, most commonly in high-grade serous tumours (3/5 cases, $60 \%)$. This is in concordance with Sylvia et al.[30]

Borderline tumours occur in younger women less than 40 years of age. To preserve fertility, conservative surgery is the treatment of choice. These patients should be monitored routinely for CA-125 serum levels and ultrasound examinations. The clinical course lies in between the benign and malignant tumours. Evidence suggests they are known to metastasize within the peritoneal cavity.

In mucinous borderline tumours, the identification of stromal invasion is difficult. This is because of gross and microscopic multiloculation. But, atypical nuclei and stratification of more than 3 layers suggests welldifferentiated mucinous carcinoma even when there is no stromal invasion.

In our study, Her-2/neu was positive (3/5 cases $60 \%$ ) in serous tumours and $1 / 3(33.3 \%)$ cases of mucinous tumours.
This is in concordance with studies of Sapna Goel et al.[23] In our study, the intensity of positivity did not correlate with age, size and grade of the tumours. This is in concordance with Sapna Goel et al[23] and Sylvia et al.[30] From the above data, Her-2/neu expression only in malignant tumours suggests their carcinogenic role and helps in distinguishing borderline and malignant tumours.

\section{CONCLUSION}

This study is an institution based one with a small sample size of 132 cases. The results may not actually reflect the original age distribution and histological pattern of ovarian tumours in Indian population. The epidemiological data of developed countries in many aspects differ from the developing nations. The differences about hormone receptors expression by different authors may be due to various parameters like case selection, method of immunehistochemistry and sample size and different grading systems. This should be standardized to identify reliable prognostic markers in the clinical trial of hormone therapy. A multicentric, large population-based study with facility of follow-up will be needed to prove the prognostic significance of anti-HER-2/neu therapy in surface epithelial carcinomas. Thus, a panel of markers will be helpful in prognostication of ovarian tumour and development of targeted therapy. This study will serve as a reference for future studies. Continued research studies in future would accomplish an effective therapy for ovarian cancer.

\section{REFERENCES}

1. Leung PC, Choi JH. Endocrine signalling in ovarian surface epithelium and cancer. Human Reproduction Update 2007;13(2):143-62.

2. Tomsova M, Melichar B. Contribution of immunohistochemistry in prognostic assessment of epithelial ovarian carcinoma-review of the literature I. Acta Medica 2006;49(3):161-5.

3. Murthy NS, Shalini S. Changing trends in incidence of ovarian cancer-the Indian scenario. Asian Pacific Journal of cancer prevention 2009;10(6)1025-30.

4. Quirk JT, Natarajan N, Mettlin CJ, et al. Risk factors for invasive epithelial ovarian carcinoma by histological subtype. Online J Health Allied Scs 2004;3(2).

5. Risch HA. Hormonal etiology of epithelial ovarian carcinoma with hypothesis concerning the role of androgens and progesterone. Journal of Natural Cancer Institute 1998;90(23):1774-86.

6. Langley FA, Fox H. Ovarian tumours classification histogenesis etiology. In: Fox H, Wells M, (eds). Obstetrical and gynaecological pathology. Newyork: Churchill Livingstone 1995:727-969.

7. Lee WH, Lew WYC. FNAC in the diagnosis and classification of recurrent and metastatic gynaecological malignancy. Sing Med J 1988;29:375-8.

8. Kurman RJ, Shih Lem. Molecular pathogenesis \& extra ovarian origin of epithelial ovarian cancer-shifting the paradigm. Human Pathology 2011;42(7):918-31.

9. Haung J, Hu W, Sood AK. Prognostic biomarkers in ovarian carcinoma. Cancer Biomark 2010-2011;8 (4-5):231-51. 
10. Ho SM. Estrogen, progesterone and epithelial ovarian cancer. Reproduction Biology and Endocrinology 2003;1:73.

11. Hogdall EV, Christensen L, Hogdall CK, et al. Prognostic value of ER, PR tumour expression in Danish ovarian cancer patients from the Malova ovarian cancer study. Oncology Report 2007;18(5):1051-9.

12. Sarkar M, Jha T, Das TK, et al. Spectrum of epithelial ovarian tumours with HER2/neu expression by the carcinomas among patients admitted in a tertiary care hospital in eastern India. International journal of medical science and public health 2015;4(10):1388-92.

13. Mills SE. Sternberg's diagnostic surgical pathology. In: Carter D, Greenson JK, Reuter VE, et al. (eds) $5^{\text {th }}$ ed. Philadelphia: Lippincott Williams and Wilkins, chapter 48, 2009;2:2005-47.

14. Mondal SK, Banyopadhyay R, Nag DR, et al. Histological pattern and clinical evaluation of 957 ovarian neoplasms: a 10-year study in a tertiary hospital of eastern India. Journal of Cancer Research and Therapeutics 2011;7(4):433-7.

15. Hiremath PB, Gane B, Meenal C, et al. Clinical profile and pathology of ovarian tumour. International Journal of Biological and Medical Research 2012;3(2):1743-6.

16. Bossard C, Busson M, Vindrieux D, et al. Potential role of estrogen receptor as a tumour suppressor of epithelial ovarian cancer. PLOS one 2012;7(9):e44787.

17. Roth LM. Recent advances in the pathology and classification of ovarian sex cord stromal tumours. Int J Gynecopathol 2006;25(3):199-215.

18. Laman S, Zaman S, Majid S, et al. A retrospective study of ovarian tumours and tumour like lesions. Journal Ayub Med Coll Abbottabad 2010;22(1):104-8.

19. Jeffray SD, Russel P, Kurman RJ. Surface epithelial tumours. In: Kurman RJ (edn). Blausteens pathology of female genital tract. $5^{\text {th }}$ ed. New York: Springer-Verlag 2002:791-881.

20. Malpica A, Deavers MT, Lu K, et al. Grading of ovarian serous carcinoma using two tier grading system. American Journal of Surgical Pathology 2004;28(4): 496-504.
21. Koonings PP, Campbell K, Mishell DR, et al. Relative frequency of primary ovarian neoplasms: a 10 year review. Obstet Gynecol 1989;74(6):921-6.

22. Mishra RK, Sharma SP, Gupta U, et al. Pattern of ovarian neoplasm in eastern UP. J Obstet Gynaecol India 1991;30:242-6.

23. Kondi-Pafiti A, Papakonstantinou E, Iavazzo C, et al. Clinicopathological characteristics of ovarian carcinoma and associated with endometriosis. Archives of gynaecology and obstetrics 2011;28(2):479-83.

24. Kwok Kkm, Loke Tkl, Hui Jpk, et al. Malignant mixed germ cell tumour of ovary in a 10 year old girl. JHK Coll Radiology 2008;11:92-5.

25. Singh P, Yordan EL, Wilbanks GD, et al. Malignancy associated with benign cystic teratomas of the ovary. Singapore Med Journal 1988;29(1):30-4.

26. Mandai M. Krukenberg tumours. CME Journal of Gynaecologic Oncology 2004;9(2):112-4.

27. Sylvia MT, Kumar S, Dasari P. The expression of immunohistochemical markers estrogen receptor, progesterone receptor, her-2/neu, p53 and ki67, in epithelial ovarian tumours and its correlation with clinicopathologic variable. Indian Journal of Pathology and Microbiology 2012;55(1):33-7.

28. Agarwal N, Rao DL, Murgeshan $\mathrm{K}$, et al. Clinical evaluation of steroid receptors in ovarian neoplasms. Int J Gynaecol Obstet 1987;25(2):145-9.

29. Damiao RD, Oshima CT, Stavale JN, et al. Analysis of the expression of ER, PR receptors and chick albumin upstream promoter transcription factor -1 in ovarian cancers. Oncol Rep 2007;18(1):25-32.

30. Buchynska LG, Lurchenko NP, Grinkevych VM, et al. Expression of ER, PR receptors as prognostic factors in serous ovarian cancers. Expression Oncol 2009;31(1): 48-51. 